\title{
Diels-Alder cross-linked, washing-free hydrogel films with ordered wrinkling patterns for multicellular spheroid generation
}

Qianbing Chen, Lei Cui, Ying Guan and Yongjun Zhang

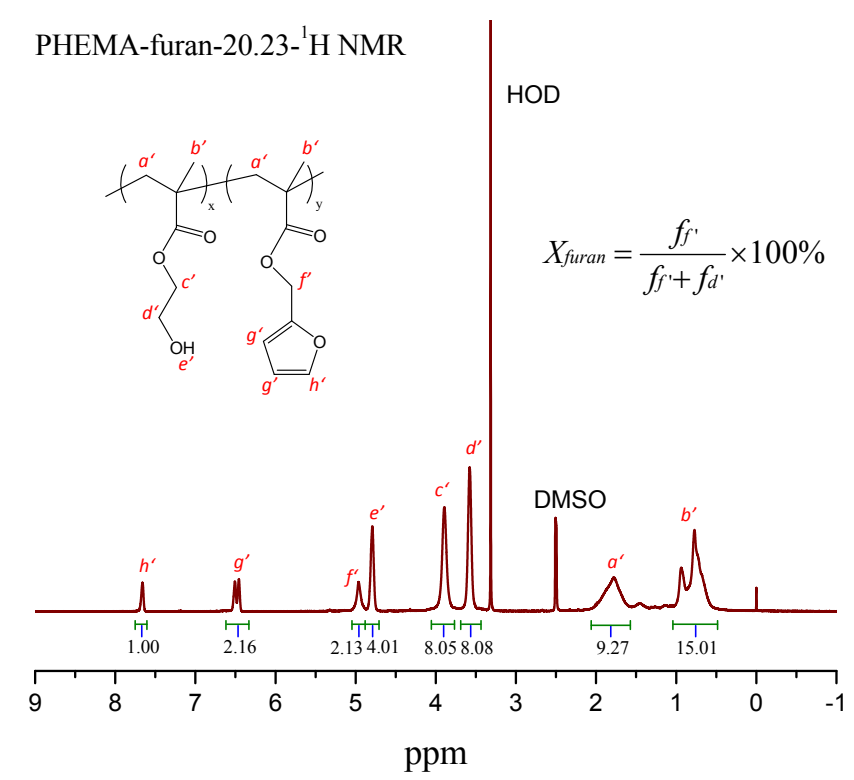

Figure S1. ${ }^{1} \mathrm{H}$ NMR spectra of PHEMA-furan-20.23. The furan content of the polymer was calculated from the integral areas of peak f' $\left(\mathrm{CH}_{2}\right.$ groups in FMA unit) and peak d' ($\mathrm{CH}_{2} \mathrm{CH} \mathrm{H}_{2} \mathrm{OH}$ groups in HEMA unit). The solvent was DMSO- $\mathrm{d}_{6}$. 


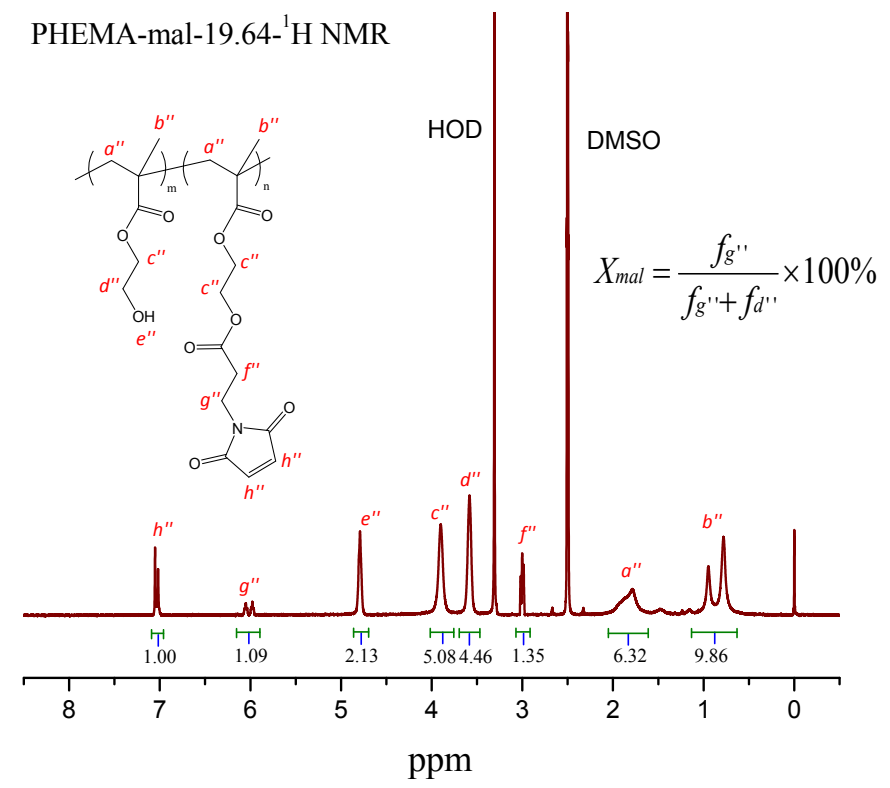

Figure S2. ${ }^{1} \mathrm{H}$ NMR spectra of PHEMA-mal-19.64. The mal content of the polymer was calculated from the ratios of the integrals of peak $g^{\prime \prime}\left(-\mathrm{CH}_{2}\right.$ groups close to the maleimide groups in MPA unit) to peak $d^{\prime \prime}\left(-\mathrm{CH}_{2} \mathrm{CH}_{2} \mathrm{OH}\right.$ groups in HEMA unit). The solvent was DMSO- $\mathrm{d}_{6}$.
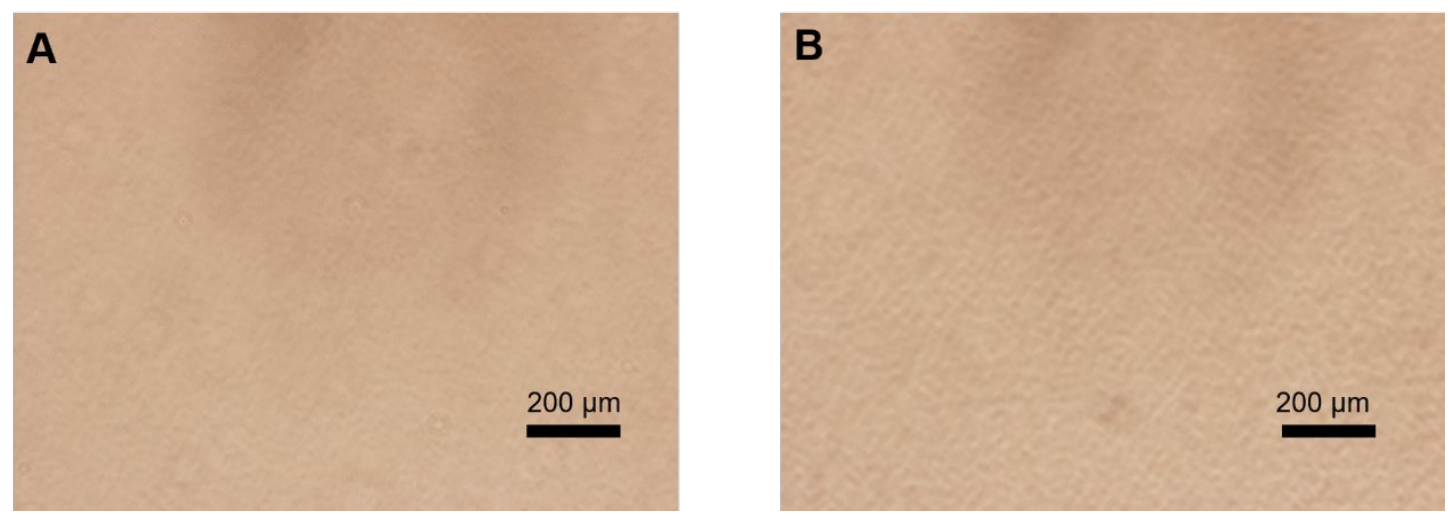

Figure S3. Micrographs of an untreated PHEMA film (A) and a thermally treated PHEMA film $\left(24 \mathrm{~h}\right.$ at $\left.75^{\circ} \mathrm{C}\right)(\mathrm{B})$ after swelling in $\mathrm{DI}$ water. 

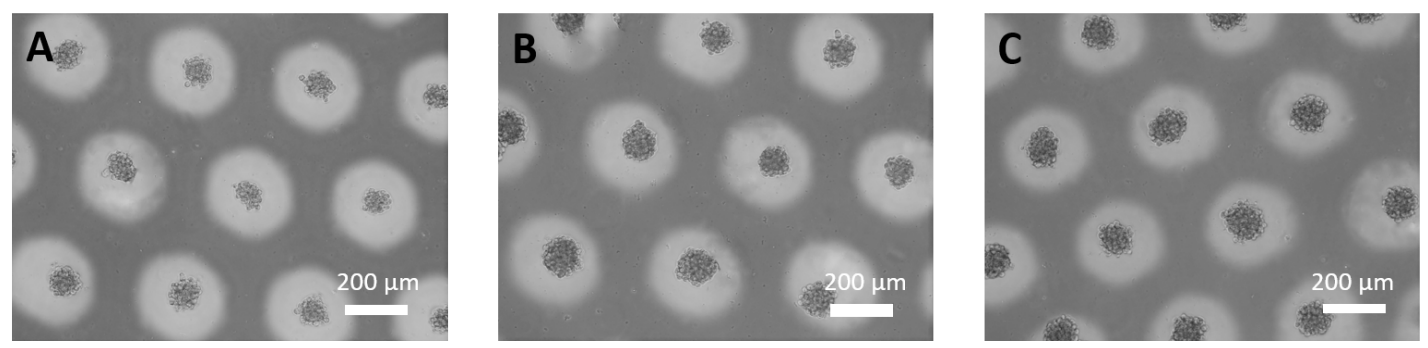

Figure S4. Optical images of multicellular spheroids of A549 cells. The spheroids were obtained by $24(\mathrm{~A}), 48(\mathrm{~B})$, and $72 \mathrm{~h}$ culture $(\mathrm{C})$ on patterned PHEMA films.
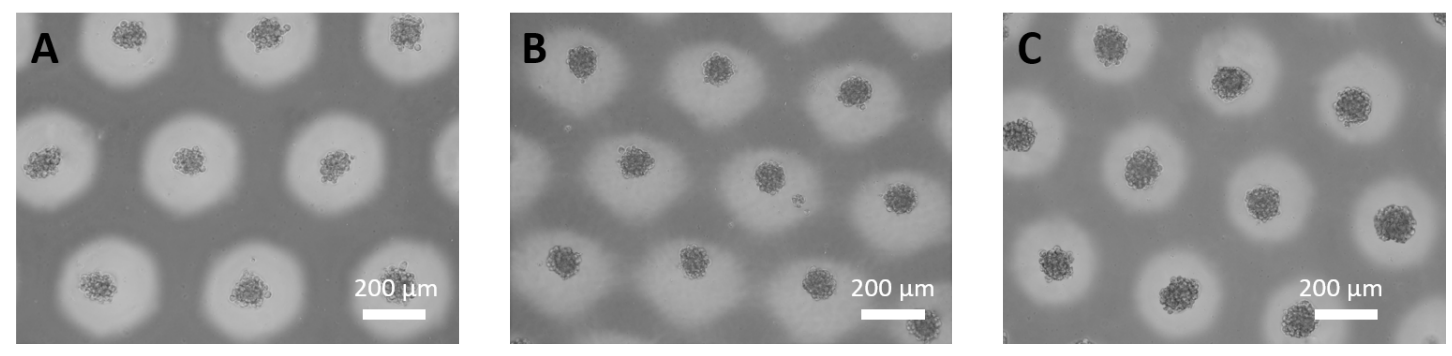

Figure S5. Optical images of multicellular spheroids of SP20 cells. The spheroids were 
obtained by $24(\mathrm{~A}), 48(\mathrm{~B})$, and $72 \mathrm{~h}$ culture $(\mathrm{C})$ on patterned PHEMA films. 